\title{
Analysis of Subject-Verb Agreement Errors in Third Person Singular Verb Forms by Spanish University Students: A Corpus-Based Study
}

\author{
Sidoní López Pérez ${ }^{1}$ \\ ${ }^{1}$ Faculty of Education, Department of Didactics of the English Language, Universidad Internacional de La Rioja, \\ Madrid and Logroño, Spain
}

Correspondence: Sidoní López Pérez, Faculty of Education, Department of Didactics of the English Language, Universidad Internacional de La Rioja, Madrid and Logroño, Spain. E-mail: sidoni.lopez@unir.net

Received: November 29, $2020 \quad$ Accepted: December 30, $2020 \quad$ Online Published: January 8, 2021

doi:10.5539/ijel.v11n2p23 URL: https://doi.org/10.5539/ijel.v11n2p23

\begin{abstract}
This study is aimed at analyzing subject-verb agreement (SVA) errors with third person singular lexical verbs in the Present Simple by Spanish higher-education students in a computerized learner corpus from Universidad Internacional de La Rioja (UNIR). The corpus is composed of 155 participants and 246 writing samples and it consists of the students' spontaneous writings in response to a compulsory online forum from the nonlinguistic subject, ICT Tools Applied to the Learning of English, which is included in the curriculum of the Degree in Early Years Education. The SVA errors found in the corpus were classified according to Dulay, Burt and Krashen's (1982) Surface Strategy Taxonomy, which groups language errors into four different types: omission, addition, misformation and misordering. The results show that the most frequent type of error made by the students is misformation, followed by misordering and by addition, which account for almost $95 \%$ of the total number of errors, whereas omission is the least frequent type of error, accounting for only $5 \%$ of all the errors. At the same time, the analysis indicates that the errors produced by the students are mainly intralingual, reflecting an inadequate or incomplete learning of the target language, and also interlingual since some errors committed by the learners are related to native language (NL) transfer. These results suggest some pedagogical implications for the teaching and learning of SVA rules which are also included in the paper.
\end{abstract}

Keywords: subject-verb agreement, present simple, 3rd person singular verb forms, Surface Strategy Taxonomy, intralingual, interlingual

\section{Introduction}

As different studies reveal, subject-verb agreement (SVA) errors are very common in the writing production of students across different educational levels, including tertiary level students (Sufian \& Osman, 2015; Tafida \& Okunade, 2016). As a result, multiple researchers have focused their analysis on SVA errors (see Vigliocco, Butterworth \& Garret, 1996; Stapa \& Izahar, 2010; Chele, 2015; Harun \& Sufian, 2015; Nurjanah, 2017; Alahmadi, 2019; Mesrawati \& Narius, 2019), and all of them agree that SVA rules continue to pose problems for learners of English. These studies generally focus on locating and analyzing SVA errors in students' writings and the results usually indicate that SVA is more problematic in the Present Simple because of the third person singular inflection (-s/-es). According to Celce-Murcia and Larsen-Freeman (1999), one of the reasons for this can be related to the fact that English language beginners tend to "simplify and leave off altogether the third person singular inflection" (p. 57). In addition, the results of the studies also reveal that the students do not often apply the third person singular inflection to other grammatical persons, and therefore, few researchers have investigated SVA with third person singular verb forms. However, in this corpus-based study, multiple students were found to use lexical verbs inflected in the third person singular form with different grammatical persons and subjects in the sentences. This indicates that the learners may be overusing the third person singular inflection in cases in which it should not apply. Hence, the present study focuses on SVA errors committed by the students when dealing with the third person singular in the Simple Present in order to analyze the misuse of this verb form and find out the causes behind the students' errors. This will allow the researcher to provide some pedagogical approaches that will be useful to improve the learners' appropriate use of SVA.

\section{Theoretical Background}

When talking about grammar, the idea of a set of rules that governs the formation and structure of sentences 
generally comes into mind. In fact, as Celce-Murcia and Larsen-Freeman (1999) highlight, "probably the most common association with the word grammar is the word rule" (p. 3). When considering grammar as a set of rules, two different tasks are usually addressed: separating sentences which are grammatical from those which are ungrammatical and "providing a description of each of the grammatical sentences" (Ndimele, 2016, p. 419). Among the long list of grammar rules in English, SVA is considered to be a problematic area for learners of a second or foreign language (L2/FL). SVA or subject-verb concord refers to "the relationship between two grammatical units such that one of them displays a particular feature (e.g., plurality) that accords with a displayed (or semantically implicit) feature in the other" (Quirk \& Greenbaulm, 1985, p. 755), which means that the subject and the verb must agree in terms of number and person.

The rule for subject-verb concord is usually very simple and it takes into consideration that a singular subject requires a singular verb and a plural subject needs a plural verb. However, it is not enough if the two items share the same properties because they need to be in the so-called "systematic covariance" (Steel, 1978, as cited in Corbett, 2006, p. 4). This means that if one of the elements is singular, the other element also needs to be singular; therefore, "if this property varies in one of the forms then it will also vary in the other" (Morales, 2014, p. 35). In addition, it is also important to keep in mind that agreement is only determined by one of the items, which is usually referred to as the "controller" (e.g., the subject noun phrase), whereas the item whose form is determined by agreement (e.g., the verb phrase) is called the "target" (Corbett, 2006, p. 4). The clause in which agreement takes place is the so-called "domain", and it can indicate different agreement "features", such as singular, plural, dual, etc., (Corbett, 2006, p. 4), as Figure 1 shows below. As Morales (2014) points out, SVA agreement can be understood "as the process by which the subject (i.e., agreement controller) comes to be expressed on the verb (i.e., agreement target)" (p. 36).

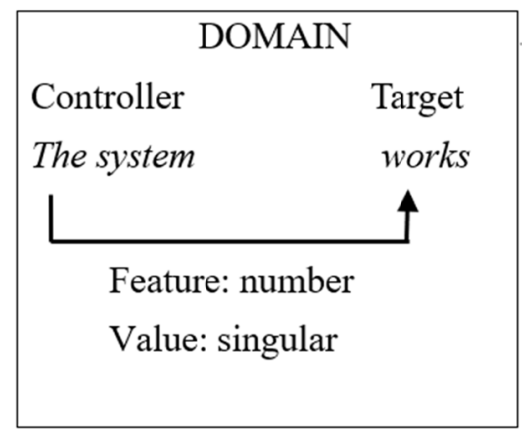

Figure 1. Agreement terms (Adapted from Corbett, 2006, p. 5)

In both English and Spanish, there are SVA rules. However, some important differences can be noticed between these two languages since Spanish has a rich verbal inflection structure whereas English has a verbal morphology, which is quite poor (Vigliocco, Butterworth, \& Garret, 1996). The Spanish language contains verb forms which are inflected and marked for number, person and tense, while in English only tense is marked. In addition, in the English language verbs in the Present Simple tense mark agreement only with the 3rd person singular, which is not the case in Spanish, in which both third person singular and plural are always marked differently. Nonetheless, although verbal inflection in English is simpler than in Spanish and the general rule for SVA in the English language is quite simple too (a singular subject takes a singular verb; a plural subject takes a plural verb), SVA is not so easy to attain and put into practice by learners of English. As Hoshino, Dussias and Kroll (2010) explain, "even highly proficient speakers producing sentences in their native language make agreement errors more often than might be expected" (p. 87). To give just a few simple examples, sometimes learners forget about the third person singular inflection (e.g., Sharon *live in Seattle); on other occasions, they tend to overgeneralize the inflection and apply it to uninflected verb forms, such as modal auxiliary verbs (e.g., Jack *ans dance disco); they also make use of the third person singular inflection with subjects in which the person and number are not appropriate (e.g., I / They / You goes to Stanford) (Celce-Murcia \& Larsen-Freeman, 1999); and finally, some students use third person singular verbs with plural subjects (e.g., The new technologies *improves creativity). In other words, learners make a wrong use of the SVA rules, giving rise to multiple errors which are worth analyzing and correcting.

Errors are considered to be a part of the natural process of learning an L2 since they reflect gaps in the learners' knowledge, and they happen because learners do not know what is correct (Ellis, 1997). Following Corder (1967, 
as cited in Ellis, 1994), errors could be relevant in three different ways: first, to provide teachers with information regarding how much learners have learnt; second, to provide researchers with evidence of how language was learnt; and thirdly, to be helpful as devices by which learners discover the rules of the target language. In other words, focusing on errors is useful for both teachers and learners (Ellis, 1997), and it is also crucial to identify and examine those errors meticulously "in order to assist students in their language proficiency" (Alahmadi, 2019, p. 51). In this sense, Error Analysis (EA), as proposed by Corder in 1974, has become one of the mostly used methods to investigate the errors that learners commit when learning an L2.

According to the literature reviewed, errors can be classified into different categories based on their various taxonomies: linguistic category, surface strategy, comparative analysis and communicative effect. One of the most frequently used categories for the analysis of SVA errors is Dulay, Burt and Krashen's (1982) Surface Strategy Taxonomy, which is based on the ways learners alter surface structures of the target language. This category is based on four types of errors: 1) omission errors, which are characterized as "the absence of an item that must appear in a well-formed structure" (e.g., Mary *president *new company) (Dulay, Burt, \& Krashen, 1982, p. 154); 2) addition errors, which are those that refer to "the presence of an item which must not appear in a well-formed utterance" (p. 156) (e.g., The amount of time *it is not enough); 3) misformation errors, which refer to "the wrong form of the morpheme or structure" (p. 158) (e.g., The new technologies *improves); and, 4) misordering errors, which are characterized by "the incorrect placement of a morpheme or group of morphemes in an utterance" (p. 162) (e.g., On the education field *happens the same).

As said before, many studies have been focused on the production of SVA errors by students of English. However, although these studies are absolutely useful to provide information about the writing production of learners of English with different mother tongue backgrounds, the samples gathered by the researchers are generally based on specific writing assignments by students of English as a Second Language (ESL) or English as a Foreign Language (EFL). This leaves unattended learners' spontaneous language production (Liu \& Gleason, 2000) as well as non-linguistic subjects (López Pérez \& Benali Taouis, 2018, 2019), without taking into consideration that the spontaneous writing production of students is "a very rich source to analyse and research about the interlanguage of learners of various language groups" (Castillo Rodríguez \& López Pérez, 2019, p. 154). Therefore, the relevance of the present study on SVA by Spanish university students lies in the fact that it focuses on the students' spontaneous written contributions to a compulsory online forum, which belongs to a computerized learner corpus at UNIR. This forum is one of the activities designed for the nonlinguistic subject, ICT Tools Applied to the Learning of English, which uses English as a Medium of Instruction (EMI) and is included in the Degree in Early Years Education at UNIR. The use of the learner corpus, also referred to as interlanguage (IL) or L2 corpus (Granger, 2003), will allow the researcher in this study to locate the frequency of third person singular lexical verbs in the Present Simple as well as to identify and analyse the errors that the students commit regarding SVA.

\section{Methodology}

\subsection{Participants and the Learner Corpus}

This research includes a cross-sectional study, which is based on a monolingual comparable corpus under the name of ENTECOR. This learner corpus is divided into two sub-corpora, TICOR and SECOR, including the writing production of 786 students from UNIR, with a total of 527,099 tokens and 13,148 types. The present study analyses SVA errors in the first sub-corpus, TICOR, which is separated into two more components: ICT, which contains the spontaneous writing pieces of 155 students from a subject in the Degree in Early Years Education, and TIC, which includes the natural writing productions of 511 students from another subject in the Degree in Primary School Education. SECOR, the second-subcorpus, is made of the spontaneous writing production of 120 learners from a subject in the Master's Degree in Secondary Education (see Table 1 below).

This research focuses on ICT, the first component of the TICOR sub-corpus, which was collected from 2014-2015 to 2015-2016 and includes the texts written by 155 students, with a total of 246 writing samples, 4,816-word types and 107,042-word tokens. These samples belong to the various contributions of the learners to a compulsory forum of the nonlinguistic subject, ICT Tools Applied to the Learning of English, which uses EMI and is totally taught in an online environment. In this forum, the students must write about the importance of using authentic materials and/or already-made materials in the ESL classroom, and the task requires a maximum of three graded contributions per each student. If the students write three posts, they can get the maximum number of points, but if they write a lower number of contributions, they will lose a part of those points. Regarding the students' level of English, it is not homogeneous, although they are required to have between A2 and B1 level according to the Common European Framework of Reference for Languages. 
Table 1. Data of the learner corpus ENTECOR

\begin{tabular}{llll}
\hline Corpus & ENTECOR & & \\
\hline Sub-corpora & TICOR & & SECOR \\
Components & ICT & TIC & TRAINCOR \\
Number of students & 155 & 511 & 120 \\
Tokens & 107,072 & 317,759 & 102,268 \\
Types & 4,821 & 9,320 & 6,380 \\
\hline
\end{tabular}

\subsection{Data Collection and Tools}

In order to collect the data in the learner corpus under investigation, that is, the ICT component, Corder's (1974) theoretical framework has been followed: identification, description, classification and explanation of errors. After collecting the samples by following different steps, such as downloading and codification, cleaning and saving, registering codes and exploitation (Castillo Rodríguez \& Díaz Lage, 2015), the first step was to carry out the initial tagging of the learner corpus through the use of TagAnt (1.2.0) (Anthony, 2015), which is a freeware tagging tool that makes it possible to tag the texts according to Parts of Speech (POS) categories. Those selected for the present study were words tagged as VVZ (lexical verbs in the third person singular in the Simple Present). After this, the term under scrutiny, that is, SVA errors with third person singular lexical verbs, was located by using the Concordance tool of AntConc (3.4.4) (Anthony, 2018), an advanced text analysis application that provides details about the multiple text files in the corpus. In order to do this, the string * VVZ was typed in the search box of the Concordance section and three different positions were assigned in order to generate lines in Key Word in Context (KWIC): 1L, 2L, 3L, which means that a three-word search span to the left was used, where $1 \mathrm{~L}$ is the first word to the left, $2 \mathrm{~L}$ is the second word to the left, and $3 \mathrm{~L}$ is the third word to the left of the node word. The string *_VVZ allowed the researcher to locate any word followed by any lexical verb in third person singular in the Simple Present, and the levels in the KWIC sort made it possible to extract words up to three positions to the left of the node in order to locate and identify the subject agreement with the verbs analyzed in the corpus. After this, the concordance lines were read very carefully so as to eliminate irrelevant cases (e.g., words in plural ending in -s (children's needs) and words which can be either nouns or verbs in the third person singular (e.g., students' faces). These words were removed from the analysis because Antconc identified them as verbs in the third person singular in the Simple Present; however, after reading carefully all the sentences, it became clear that these words were just nouns and only those sentences which contained lexical verbs in the Present Simple tense, third person singular, were located and included in the analysis. The next step consisted of extracting all those sentences manually from the corpus and scrutinizing the lines very carefully so as to locate and identify instances of SVA errors. Finally, all the SVA errors were classified according to Dulay, Burt and Krashen's (1982) Surface Strategy Taxonomy, which groups language errors into four different types: omission, addition, misformation and misordering. After this, the sources of these errors were analyzed and classified into the major causes of error, that is, interlingual and intralingual errors, following Brown's (2000) classification.

Regarding the examples of SVA errors in the corpus, all of them are verbatim and presented in tables that include the details and codes employed in the learner corpus: the hit number, the example, the student identification number, the source text (TO), the language (English: EN), the subject (ICT), and the forum of all the sections of this subject that includes two compulsory forums during the academic year (letter A stands for forum 1; letter B stands for forum 2). At the same time, all SVA errors will be presented in bold and a corrected version will also be provided for each example.

\section{Results and Discussion}

In the learner corpus used for this study, which consists of 155 writing pieces and 107,072 tokens, 813 hits were retrieved by the string * VVZ, out of which 168 sentences were removed because they were irrelevant cases, as explained previously. Thus, the total number of sentences that was analyzed in search for SVA errors in the Present Simple, third person singular lexical verbs, was 645 . As a result of the analysis carried out in order to detect this type of error, 39 examples were located in which the students made a wrong use of SVA with third person singular verbs in the Simple Present. This indicates that SVA with this kind of verbs is used incorrectly in $6.04 \%$ of the cases. Even though this percentage is not very high, it demands our attention because it certainly indicates that SVA rules continue to be an area of difficulty for Spanish students. As said before, in order to analyze and classify SVA errors in the corpus, Dulay, Burt, and Krashen's (1982) Surface Strategy Taxonomy 
was used by focusing on omission, addition, misformation and misordering errors, as Table 2 indicates below.

Table 2. Error classification in the corpus

\begin{tabular}{lllll}
\hline Hits retrieved by the string *_VVZ & 813 & & & \\
Irrelevant cases & 168 & & & \\
Examples of SVA & 645 & & & \\
Classification of errors & Omission & Addition & Misformation & Misordering \\
Number of errors & 2 & 3 & 25 & 9 \\
Total number of errors & & 39 & & \\
\hline
\end{tabular}

As seen from the results of the analysis focused on the Surface Strategy Taxonomy, two errors were found in the omission category, three errors were located in addition, 25 errors were found in misformation, and nine errors were located in misordering. Each of them will be explained in detail below.

\subsection{Errors of Omission}

Errors of omission are those that refer to "the absence of an item that must appear in a well-formed structure" (Dulay, Burt, \& Krashen, 1982, p. 154). In the learner corpus, only two omission errors out of a total of 39 were identified, which means that SVA was used incorrectly in $5.12 \%$ of the cases, accounting for the lowest number of errors in this study. The following examples extracted from the corpus illustrate this type of mistakes.

Table 3. Errors of omission in the learner corpus

\begin{tabular}{llll}
\hline Hit number & Examples & Correct form & Student ID \\
\hline 412 & I think that both materials, *provides Internet and activities that & $\begin{array}{l}\text { (those) provided on the } \\
\text { internet } \\
\text { we can design, have advantages and disadvantages. }\end{array}$ & 20TOENICTB \\
& $\begin{array}{l}\text { Today we have to prepare educational material with ICT *takes } \\
\text { a lot of time ... }\end{array}$ & 108TOEN & \\
\hline
\end{tabular}

In the examples above the students clearly omitted items and grammar structures that make those sentences incorrect. In hit 412, the learner needs an explanatory sentence that makes reference to the type of materials he/she is talking about, whereas in hit 187, the sentence requires a non-defining relative clause, which consists of a relative pronoun (which) and a verb in the third person singular (takes). These errors seem to be intralingual because they are produced "within the target language itself" (Brown, 2000, p. 224). In the two examples, the omission errors include the absence of different items to get the sentences correct (e.g., subject + verb + adjunct in hit 412 and a relative pronoun + a verb in hit 187), which may indicate that the learners still have a limited linguistic knowledge of the target language. In addition, they resort to simplification as they seem to "choose simple forms and constructions instead of more complex ones" (Touchie, 1986, p. 78).

\subsection{Errors of Addition}

Addition errors are identified by "the presence of an item which must not appear in a well-formed sentence" (Dulay, Burt, \& Krashen, 1982, p. 156). In this case the students committed errors of addition in three sentences out of 39, which means that they made a wrong use of SVA in $7.69 \%$ of the cases. These errors consist basically of simple additions that have been classified into three different categories: a) addition of the pronoun $i t$, b) addition of the verb to be, and c) addition of the auxiliary verb does. The following table shows the number of errors in each category.

Table 4. Errors of addition in the learner corpus

\begin{tabular}{llll}
\hline Classification of errors & It & Verb to be & Auxiliary verb does \\
\hline Number of errors & 1 & 1 & 1 \\
Total number of errors & & 3 & \\
\hline
\end{tabular}

\section{A) Addition of the pronoun it}

Regarding the errors of addition with it, one case out of three has been identified, which indicates that SVA was used wrongly in $3.33 \%$ of the cases. This example is shown in Table 5 below. 
Table 5. Errors of addition with $i t$

\begin{tabular}{llll}
\hline Hit number & Examples & Correct form & Student ID \\
\hline 350 & , which *it means ... & which means & 74TOENICTA \\
\hline
\end{tabular}

In this example, it needs to be deleted as its use makes the sentence incorrect. In hit 350, the student used the verb means, which is appropriate to make the sentence accurate. However, the learner provided the pronoun it thinking it was necessary to make his/her sentence correct, while he/she does not seem to realize that this element should be left out because it does not have any function within the sentence. It rather seems that the student is using it as a subject without taking into consideration that the phrase preceding the pronoun is already the subject in the sentence. Therefore, this erroneous addition of $i t$ could be classified as a double-marking error, since "two items rather than one are marked for the same feature" (subject, in this example) (Dulay, Burt, \& Krashen, 1982, p. 156). The error of addition in this first category could also be considered as an intralingual error as the student is clearly producing an error within the language itself when writing a sentence that does not have a correct subject-verb structure.

B) Addition of the verb to be

In this second category, one example was located out of three errors as well, indicating that SVA was used incorrectly in $3.33 \%$ of the cases in the corpus. Table 6 shows this example below.

Table 6. Errors of addition with to be

\begin{tabular}{llll}
\hline Hit number & Example & Correct form & Student ID \\
\hline 68 & $\ldots$ the majority of us *be agrees ... & the majority of us agree & 62TOENICTA \\
\hline
\end{tabular}

In hit 68 , the learner included the verb to be in its bare infinitive form (be) after the subject, which indicates a clear error in SVA, and after this he/she used the verb to agree in the third person singular present simple, which is not the right form either to make the sentence accurate. In hit 68 , the word majority is not a single unit, which means that the verb that comes after it must be plural, not singular. The fact that majority is followed by the object pronoun us suggests that the situation of several students within that unit is spoken about, which implies the use of plural verb form (agree). At the same time, us makes reference to the first-person plural pronoun we; therefore, a verb in its plural form should be mandatory in the sentence. This indicates that common confusions can arise in our students when dealing with collective terms, such as majority, which again seems to reflect an intralingual error. However, the learner also made use of the verb to be with the verb to agree, which is something incorrect in English, but accurate in Spanish. In other words, the verb to agree in Spanish requires the verb to be (estar de acuerdo); otherwise, the sentence will be wrong and ungrammatical. Multiple examples regarding the use of to be with the verb to agree have been found in the corpus and this is why they have been analyzed and researched about separately by Castillo Rodríguez and López Pérez (2019), concluding basically that these mistakes are mainly due to NL transfer or interference. In the examples found in the corpus, as well as in hit 68 in the present analysis, "our students are making a literal translation from their mother tongue to the FL and the results include multiple errors in the conjugation of the structure to agree" (Castillo Rodríguez \& López Pérez, 2019, p. 166). Thus, the use of be after the majority of us in the sentence above implies a clear interlingual error.

\section{C) Addition of the auxiliary verb does}

The third classification of the errors of addition in the corpus corresponds to the auxiliary verb does, which in this case appears in an indirect question in hit 351, indicating one more time that SVA was used wrongly in 3.33\% of the cases in the learner corpus. Table 7 contains this example below.

Table 7. Errors of addition with does

\begin{tabular}{llll}
\hline Hit number & Examples & Correct form & Student ID \\
\hline 351 & $\ldots$ we use it knowing what *does it means. & what it means & 15TOENICTA \\
\hline
\end{tabular}

The student made use of does without taking into consideration that indirect questions do not use the auxiliary verbs do, does or did. This implies that the learner was clear about SVA in the sense that the subject (it) is singular and the verb (means) is singular as well. However, the student used the structure of a direct question by 
adding does, and then he/she added the 3rd person singular morpheme $(-s)$ to the lexical verb mean. This is a clear intralingual error that seems to stem from overgeneralization, "a process that occurs as the second language learner acts within the target language, generalizing a particular rule or item in the second language - irrespective of the native language - beyond legitimate bounds" (Brown, 2000, p. 96). In this case, the student overgeneralized the rule of direct questions in the present simple in which case it is necessary to use the auxiliary verb does with the third person singular (e.g., what does it mean?). At the same time, he/she also overgeneralized the rule of the $-s$ morpheme for the third person singular for affirmative sentences in the present simple because the learner also used means, which is inaccurate and ungrammatical after does.

\subsection{Errors of Misformation}

As Dulay, Burt and Krashen (1982) explain, misformation errors consist of "the wrong form of the morpheme or structure" (p. 158). Contrary to omission errors in which the learner omits an item which is necessary in the sentence, in errors of misformation the learner supplies an item, although it is wrong and inaccurate. As will be shown, misformation errors account for the highest number of errors committed by the students in the learner corpus regarding SVA. In this case, the total number of misformation errors is 25 out of 39 , which means that SVA was used wrongly in $64.10 \%$ of the cases. These errors have been divided into three different categories: a) disagreement with grammatical person and number, b) inappropriate items, which is divided into two sub-categories: verbs instead of a noun and others, and c) wrong (to)-infinitive structures. The number of errors in each category is shown below.

Table 8. Errors of misformation in the learner corpus

\begin{tabular}{llllll}
\hline Classification of errors & $\begin{array}{l}\text { Disagreement with } \\
\text { grammatical person and } \\
\text { number }\end{array}$ & $\begin{array}{l}\text { Verbs instead } \\
\text { of a noun }\end{array}$ & $\begin{array}{l}\text { Inappropriate } \\
\text { items }\end{array}$ & Others & $\begin{array}{l}\text { Wrong to-infinitive } \\
\text { structures }\end{array}$ \\
\hline $\begin{array}{l}\text { Number of errors in each } \\
\text { category }\end{array}$ & 19 & 2 & & 1 & 3 \\
\begin{tabular}{l} 
Total number of errors \\
\hline
\end{tabular} & & 25 & & \\
\hline
\end{tabular}

\section{A) Disagreement with grammatical person and number}

As seen above, errors regarding the disagreement with grammatical person and number account for the highest number of misformation errors committed by the students. There are 19 errors out of 25 , which indicates that SVA was used incorrectly in $76 \%$ of the cases. Table 9 illustrates all these examples below.

Table 9. Errors of misformation in disagreement with grammatical person and number

\begin{tabular}{|c|c|c|c|}
\hline Hit number & Examples & Correct form & Student ID \\
\hline \multirow[t]{2}{*}{$41 / 784$} & I think both tools, both which *manufactures and & which manufacture and design & 20TOENICTB \\
\hline & $*$ designs $\ldots$ & & 20TOENICTB \\
\hline 78 & $\ldots$ it can * gives $\ldots$ & Give & 124TOENICTB \\
\hline 87 & $\ldots$ and test before the children *uses it. & use it & 79 TOENICTB \\
\hline 111 & This is why teachers currently *plays ... & Play & 108TOENICTB \\
\hline 160 & I *thinks ... & Think & 67TOENICTA \\
\hline 161 & I *means ... & Mean & 95TOENICTA \\
\hline 356 & $\ldots$ and kids *loves... & Love & 116TOENICTB \\
\hline 648 & , something that *don't happens. & doesn't happen & 108TOENICTB \\
\hline 670 & Education and [sic] way of teaching *evolves ... & Evolve & 16TOENICTB \\
\hline 673 & The new technologies *improves... & Improve & 63TOENICTA \\
\hline \multirow[t]{2}{*}{674} & The new technologies *makes easier a communication & make the communication between & 63TOENICTA \\
\hline & between teachers and students. & teachers and students easier & \\
\hline 688 & $\ldots$ to practice deeply other activities that *implies ... & Imply & 12TOENICTA \\
\hline 724 & $\ldots$ (those that *requires students [sic] activity [sic]) & Require & 15TOENICTA \\
\hline 759 & $\ldots$ that ICT tools *offers. & Offer & 75TOENICTA \\
\hline 760 & $\ldots$ that ICT tools *helps teachers ... & Help & 13TOENICTA \\
\hline 761 & $\ldots$ the [sic] ICT tools *offers. & Offer & 65TOENICTA \\
\hline 771 & $\ldots$ as those who we *offers. & Offer & 94TOENICTB \\
\hline 788 & I read the last interventions, which *speaks about ... & Speak & 72TOENICTB \\
\hline
\end{tabular}


As the occurrences above show, there is a clear disagreement of subject and number in the sentences that the students wrote. In most of the examples all the verbs in third person singular in the Present Simple were used with plural subjects, something which is inaccurate and ungrammatical in the English language as well as in the students' NL (Spanish). As explained before, the rule for SVA in English is very simple: a singular subject requires a singular verb and a plural subject needs a plural verb. In this case, the students wrote 14 sentences that contain a plural subject followed by a singular verb, which indicates that the learners are aware of the fact that some verbs must take the $-s /-e s$ inflection in the Present Simple. However, they seem to have forgotten that this only applies to the third person singular. This error may be due to overgeneralization since the students seem to be applying the rule of third person singular Present Simple verbs to subjects in the sentences, which are neither third person nor singular. At the same time, as Celce-Murcia and Larsen-Freeman (1999) explain, this could also be related to the fact that some learners interpret the $-s$ morpheme as a plural marker to be used on the verb when they are dealing with plural subjects.

Among all these examples, it is particularly interesting to note the structure or pattern that one of the students followed in order to write his/her sentence in hit 674. As explained before, the learner used a verb in its third person singular form with a plural subject (the new technologies *makes *easier a communication between teachers and students), but at the same time, the order of the elements in the sentence is not correct. In this case, the learner employed a causative structure with the verb make, which requires a specific structure: make + object + adjective (e.g., make something easy). However, the student used the adjective after the verb and before the object, producing an inaccurate and ungrammatical sentence, which indicates an error of misordering in the elements of the sentence. Although this error does not really have to do with SVA, it is important to point it out because even if the error in SVA were corrected, the sentence would not be grammatically correct.

In addition, it is also important to deal with the sentence in hit 648 as the learner used the auxiliary don't with a third person singular subject, and right after it he/she added the third person singular $-s$ morpheme to the lexical verb (happens). This indicates that the student is confused with or mixed up about the rules of SVA for third person singular verbs in the Present Simple. On the one hand, the learner seems to be aware of the fact that something is a singular subject because he/she makes use of the $-s$ inflection in the main verb (happens). On the other, the student seems to be not very clear about the use of doesn't for the third person singular as he/she uses don't. As a result, the sentence is not accurate and the learner makes an error in SVA because he/she does not use the auxiliary verb and the lexical verb in the right way, which again could be caused by partial or faulty learning of L2.

Finally, hits 160 and 161 are also worth noting since the students made use of third person singular Present Simple verbs with a grammatical person which is singular, but it is not the third person. In the sentences, $I$ *thinks and $I$ *means, the learners are dealing with the first person singular, which requires a verb in its base form (e.g., I think and I mean). This error leads the researcher to think that the learners are overgeneralizing the rule of third person singular verbs in the Present Simple once again.

\section{B) Inappropriate items}

Misformation errors with inappropriate items were located in three cases, which is quite a low number when compared to the first sub-category above. In this case, these errors indicate that SVA was not used correctly in $12 \%$ of the sentences in the learner corpus. As Table 10 shows below, these errors have been classified into two sub-categories: a) verbs instead of a noun, and b) others.

Table 10. Errors of misformation with inappropriate items

\begin{tabular}{llll}
\hline \multicolumn{2}{l}{ Verbs instead of a noun } \\
\hline Hit number & Examples & Correct form & Student ID \\
141 & $\ldots$ communicate or transmit feelings, *thinks, ideas ... & thoughts & 25TOENICTB \\
493 & $\ldots$, according to Rocío [sic] and Mirens [sic] *believes ... & beliefs & 116TOENICTB \\
\hline
\end{tabular}

Others

\begin{tabular}{llll}
\hline Hit number & Examples & Correct form & Student ID \\
\hline 354 & $\ldots$ and *its implies too much time. & it & 80TOENICTB \\
\hline
\end{tabular}


As can be observed, in the first two examples, the students used two verbs in the third person singular $\left({ }^{*}\right.$ thinks and *believes) as if they were nouns (thoughts and beliefs), which indicates that they do not differentiate between the form of the verbs and the form of the nouns. In the last sentence, hit 354, the student made use of the possessive pronoun its, without noticing that the right option is the subject pronoun $i t$, which implies that the learner is not clear about the difference between the possessive and the subject pronoun. In all three cases, the errors are produced within the target language, that is, they are intralingual errors which seem to be due to the overgeneralization of some rules: in the first two cases the students overgeneralized the forms of the verbs and applied them to the nouns by adding the -s plural morpheme, and in the second one, the learner overgeneralized the use of the possessive pronoun and used it in a sentence in which the subject pronoun is needed.

\section{C) Wrong (to)-infinitive structures}

The last category in misformation errors corresponds to the wrong use of SVA with grammar structures that require (to)-infinitive patterns. In this case, three examples were found out of 25 , which indicates that the students did not use SVA correctly in $12 \%$ of the sentences. Table 11 below illustrates the sentences that contain this type of errors.

Table 11. Errors of misformation with wrong (to)-infinitive structures

\begin{tabular}{llll}
\hline Hit number & Examples & Correct form & Student ID \\
\hline 190 & $\ldots$ you want the information *appears ... & to appear & 55TOENICTB \\
757 & $\ldots$ in order to *motivates students ... & to motivate & 96TOENICTA \\
472 & $\ldots$ if we want the project *ends ... & to end & 141TOENICT \\
\hline
\end{tabular}

In both hits 190 and 472, the students made use of third person singular verbs in the Present Simple after a singular subject. However, this structure is not accurate in these examples because the students used the verb want, which requires a to-infinitive pattern: subject + want + object + to-infinitive. The learners followed the right structure of subject + want + object, but they failed to include a verb in infinitive with to after the verb want. In addition, in hit 757 , the student used a third person singular verb with a structure that requires an infinitive as well (in order to + infinitive). In these three examples, the source of the errors seems to have been caused by the overgeneralization of the rule of third person singular verbs, since the learners overused this rule and applied it to cases in which such rule is incorrect.

\subsection{Errors of Misordering}

Misordering errors refer to "the incorrect placement of a morpheme or group of morphemes in an utterance" (Dulay, Burt, \& Krashen, 1982, p. 162). In the learner corpus nine errors of misordering were identified out of 39, which means that they account for $23.07 \%$ of the total errors located in this study. As can be seen in Table 12 below, misordering errors have been classified into different types: a) affirmative and negative declarative sentences; b) indirect questions; and, c) relative clauses.

Table 12. Errors of misordering in the learner corpus

\begin{tabular}{llll}
\hline Classification of errors & Affirmative and negative declarative sentences & Indirect questions & Relative clauses \\
\hline Number of errors & 5 & 1 & 3 \\
Total number of errors & 9 & & \\
\hline
\end{tabular}

\section{A) Affirmative and Negative Declarative sentences}

There are five errors out of nine in SVA in affirmative and negative declarative sentences, which account for the highest percentage of misordering errors in the corpus, that is, $55.55 \%$. As will be seen in Table 13 below, although the rules of SVA were correctly applied in most of the cases (singular subject + singular verb), the main problem lies in the fact that the students wrote the verb before the subject, which is ungrammatical in the English language. 
Table 13. Errors of misordering in affirmative and negative declarative sentences

\begin{tabular}{|c|c|c|c|}
\hline Hit number & Examples & Correct form & Student ID \\
\hline 24 & , always *appears the same contents. & the same contents always appear & 76TOENICTB \\
\hline 68 & $\ldots$ as companion *says Ana Cristina, $\ldots$ & as classmate Ana Cristina says & 56TOENICTB \\
\hline 142 & On the education field *happens the same. & the same happens/it happens the same & 61TOENICTB \\
\hline 738 & $\begin{array}{l}\text { We cannot consent *that there gets lost the } \\
\text { utilization of the physical books. }\end{array}$ & $\begin{array}{l}\text { We cannot allow the use of physical } \\
\text { books to be lost }\end{array}$ & 131TOENICTB \\
\hline 782 & $\begin{array}{l}\text {, I agree totally [sic] with what *comments on } \\
\text { us Davinia... }\end{array}$ & $\begin{array}{l}\text { I totally agree with what Davinia } \\
\text { comments about / tells us about }\end{array}$ & 131TOENICTA \\
\hline
\end{tabular}

In hits $24,68,142$ and 782 the students placed the verb before the subject, something which is quite common in Spanish, but inaccurate in English. In the Spanish language the subject + verb structure is not so strict and sometimes the verb can appear after the subject (e.g., En el campo de la educación ocurre (verb) lo mismo (subject)). This sentence was literally translated from Spanish into English by the student in hit 142 (on the education field *happens the same). This also occurs in the rest of the sentences in which the learners are clearly following the structure of their NL, clearly implying that these errors are interlingual and basically due to NL transfer. In addition, in hit 24 the student added the $-s$ for the verb in the third person singular (*appears) without taking into consideration that the subject is plural (the contents), which is also a misformation error.

In the case of hit 738 , however, which is a negative sentence, the structure used by the student is not accurate in English and neither is in Spanish. The main problem lies in the fact that the learner wants to use the verb consent with a that-clause, something which is not correct in English because this verb is generally followed by a to-infinitive or a noun. However, the verb consent is usually followed by a that-clause in Spanish (e.g., consentir $q u e$ ). This can suggest that the learner was thinking about using a similar structure to his/her NL. Yet, the pattern that the student followed after that is not accurate or grammatical in Spanish either. In fact, what the student wrote makes no sense in Spanish whatsoever. Therefore, it can be concluded that the main problem in the learner's sentence is that he/she used a verb (consent), which is not correct and appropriate for this sentence in English, but it is in Spanish. This implies two types of errors: interlingual because the student started to use a similar structure to Spanish, and intralingual because he/she does not know how to use the verb consent in a sentence in English because in this case, other verbs, such as allow, are more appropriate.

\section{B) Indirect questions}

There is only one case out of nine in which a misordering error was located with an indirect question, which means that SVA was used incorrectly in $11.11 \%$ of the cases. This example is illustrated in Table 14 below.

Table 14. Error of misordering with an indirect question.

\begin{tabular}{llll}
\hline Hit number & Examples & Correct form & Student ID \\
\hline 140 & ... how fast * changes our society. & how fast our society changes & 95TOENICTA \\
\hline
\end{tabular}

In this sentence, SVA is accurate and correct (society is singular and the verb is singular as well). However, the order of the subject and the verb is not correct as this is an indirect question and the order is just the opposite, that is, subject + verb. In this case, the student wrote the verb first and the subject afterwards (how fast * changes our society), which is ungrammatical in English, but accurate and correct in Spanish. This indicates once again that the student is relying on his/her NL to write a sentence in English, which is correct in Spanish, but ungrammatical in the target language, suggesting an interlingual error that might be caused by the negative influence of the learners' NL.

\section{C) Relative clauses}

Errors of misordering were found in three relative clauses out of nine, indicating that SVA was used wrongly in $33.33 \%$ of the cases. In these examples, which are shown in Table 15 below, the students wrote the verb first and the subject afterwards as in the two categories above. 
Table 15. Errors of misordering in relative clauses

\begin{tabular}{llll}
\hline Hit number & Examples & Correct form & Student ID \\
\hline 787 & I like the idea which *tells Itxaso. & Itxaso tells about & 03TOENICTBA \\
709 & $\ldots$. the great opportunity that *gives us ICTs. & ICTs give us & 40TOENICTA \\
712 & To the question that *makes us Davinia ... & Davinia asks us about & 131TOENICTB \\
\hline
\end{tabular}

As said before, although the verb + subject structure is ungrammatical in English for positive and negative sentences, it is accurate and correct in Spanish. In fact, the students seem to have literally translated these three sentences from Spanish into English, resulting in a clear negative NL transfer, which has contributed to writing inaccurate and ungrammatical sentences in the English language. In the first and third sentence (hits 787 and 712), the rule of SVA was correctly applied since the students dealt with singular subjects and singular verbs. In spite of this, the students wrote the proper names of their classmates after the verb, which is something common in Spanish, but incorrect in English as the order in these sentences needs to be subject + verb, not the other way around. At the same time, in the first sentence the learner used the verb tell without the preposition about, which is required in this example because the student is describing his/her idea to his/her classmates. However, in the third sentence, the learner used the verb make to indicate that one of his/her classmates was asking a question, which could be considered a collocation error because in English you usually ask questions, but you do not *make questions as is the case in Spanish. This indicates an interlingual error produced by the students' NL interference. In addition, in the second example (hit 709), the learner did not just place the verb before the subject in an affirmative sentence, but he/she also made a mistake in SVA because the subject is plural and he/she wrote a verb in its singular form ( ${ }^{*}$ gives us ICTS). This is a clear intralingual error that seems to stem from the fact that the learner did not realize that the word ICTs is plural, not singular; therefore, the third person singular morpheme $(-s)$ cannot be added to the lexical verb give as it is incorrect. The confusion between the term ICT (singular) and ICTs (plural) is a very common feature found in the corpus, which has contributed to many errors (see Torrado-Cespón \& Díaz Lage, 2017).

\section{Conclusions and Pedagogical Implications}

As seen from the results and analysis above, SVA continues to be an area of difficulty for the Spanish students who were included in this research. SVA with third person singular verb forms was analyzed and the results reveal that the students made mistakes in 39 examples. These errors were classified according to the Surface Taxonomy Perspective proposed by Dulay, Burt and Krashen (1982), and the findings indicate that misformation is the most common form of error, accounting for $64.10 \%$ of the total number of errors, followed by misordering, which represents $23.07 \%$ of all the errors, and by addition, which makes up $7.69 \%$. Finally, omission is the least frequent type of error, accounting for only $5.12 \%$ of all the errors found in the learner corpus. Regarding misformation errors, an extensive overuse of the 3rd person singular morpheme $(-s)$ is found with plural subjects, indicating that the students are overgeneralizing the use of 3rd person singular verb forms and extending it to verbs whose subjects are plural. These types of errors are clearly intralingual because they are produced within the target language itself. As for misordering, the results indicate that in most of the cases the agreement between person and number is accurate, but the students failed to provide a correct order for the subject and verb in the examples, which results in clear ungrammatical sentences. Contrary to misformation, errors of misordering are mostly related to NL transfer and clearly reflect a negative influence of the students' L1 since in Spanish the order of the subject and the verb can be altered easily in most sentences. Regarding addition, different intralingual errors are found after locating items which must not appear in accurate and grammatical sentences and that result in a wrong use of SVA rules. These error types clearly indicate that the learners' domain of L2 is still faulty and partial. Lastly, omission errors, although constituting the lowest number of errors in the learner corpus, indicate that the students continue to omit items which are necessary to form accurate and grammatical sentences, especially regarding SVA. These errors are also intralingual and reflect inadequate or incomplete learning of the target language.

All in all, the results of this analysis indicate that SVA should be given due attention because the students seem to understand the 3rd person singular present ending, but the main problem is that they are using it in multiple contexts where it should not apply. As has been seen, in most of the cases the learners in the corpus used 3rd person singular verb forms as an agreement marker with subjects of inadequate person and/or number. This implies a clear overuse of this type of verb endings that calls for some pedagogical and teaching strategies that help our students improve SVA rules when writing. To start with, learners could be given different sentences, which include both singular and plural subjects in a column and verbs in the present simple (both 3rd person singular verb forms and bare infinitive forms for the rest of the persons) in another column. Students should first 
identify and underline the subjects and decide whether they are singular or plural. As Celce-Murcia and Larsen-Freeman (1999) explain, learners could do this by saying “"'one" if the subject is singular and "more than one" if the subject is plural" (p. 71). After this, they would need to choose the appropriate verb form (singular or plural) and make a whole grammatical sentence. This exercise could be first done as a writing activity and then it could be practiced by speaking to make sure students are using a correct SVA when having conversations in English as well. A similar activity could be carried out with a multiple-choice exercise in which the students are provided with different sentences which contain subjects in singular or in plural and they need to choose the correct verb after identifying the number of the subject. In addition, since some expressions of quantity can be confusing with SVA (e.g., the majority of), we could also explain about these expressions by creating three tables or columns: the first column would include expressions of quantity, such as most of, the majority of, some of, a lot of, half of, which can be singular or plural depending on the noun that follows them; the second column could include expressions which are always singular, such as the number of, each of, every (one of), one of; and, the third column would include expressions which are always plural, such as a number of. After this, one example should be provided with each expression and the learners would need to identify the subject and the verb and explain why they are singular or plural. Finally, they could be asked to construe their own sentences either by speaking or writing to make sure they are using SVA correctly. On the other hand, as it is important that students practice with the 3rd person singular present simple and contrast it with other persons, Celce-Murcia and Larsen-Freeman (1999) also propose an exercise with a fictional character (e.g., Jack) that the learners could use to talk about his daily actions and activities, whilst comparing them to theirs. This activity could also be practiced by speaking or by writing. At the same time, it would also be a good idea to provide the students with different sentences that contain SVA errors so that they could analyze and correct them. Sometimes these errors could be created and provided by the teacher himself, but on other occasions, the learners could be given a list of SVA errors from students' writings so that peer correction and learning could be encouraged. This could contribute to raising their awareness about this type of errors, whilst also providing a space for explanation and discussion by the teacher if required.

\section{Acknowledgments}

This work has been carried out in the frame of the emerging research project "Detección y análisis del comportamiento lingüístico de producciones escritas de estudiantes universitarios" (Project Reference: B0036-1617-104-ETEL. Universidad Internacional de La Rioja, 2016-2018).

\section{References}

Alahmadi, N. (2019). A Study of Grammatical Errors of Subject Verb Agreement in Writing Made by Saudi Learners. International Journal of English Language and Linguistics Research, 7(6), 48-59.

Anthony, L. (2015). TagAnt (Version 1.2.0) [Computer Software]. Tokyo, Japan: Waseda University. Retrieved from https://www.laurenceanthony.net/software/tagant/

Anthony, L. (2018). AntConc (Version 3.4.4) [Computer Software]. Tokyo, Japan: Waseda University. Retrieved from https://www.laurenceanthony.net/software

Brown, D. H. (2000). Principles of language learning \& teaching (4th ed.). New York: Longman

Castillo Rodríguez, C., \& Díaz Lage, J. M. (2015). Exploitation of a learner corpus: Analysing opening and endings in academic forums. Revista Opcion, 31(6), 192-210.

Castillo Rodríguez, C., \& López Pérez, S. (2019). To be or not to be...? Analysis of misuses with be in a learner corpus in an online environment. Revista de Filología, 39, 153-170. https://doi.org/10.25145/j.refiull.2019.39.06

Celce-Murcia, M., \& Larsen-Freeman, D. (1999). The Grammar Book: An ESL/EFL Teacher's Course (2nd ed.). Boston, MA: Heinle \& Heinle Publishers, 1999.

Chele, I. M. (2015). An analysis of subject agreement errors in English: The case of third year students at the National University of Lesotho. Ghana Journal of Linguistics, 4(1), 32-40. https://doi.org/10.4314/gjl.v4i1.

Corbett, G. G. (2006). Agreement. Cambridge: Cambridge University Press.

Corder, S. P. (1974). Error analysis. In J. Allen \& S. P. Corder (Eds.), The Edinburgh Course in Applied Linguistics (Vol. 3). Oxford: Oxford University Press.

Dulay, H., Burt, M., \& Krashen, S. (1982). Language two. Oxford: Oxford University Press.

Ellis, R. (1994). The study of second language acquisition. Oxford: Oxford University Press. 
Ellis, R. (1997). Second language acquisition. Oxford: Oxford University Press.

Granger, S. (2003). Error-tagged learner corpora and CALL: A promising synergy. CALICO Journal, 20(3), $465-480$.

Hoshino, N., Dussias, P. E., \& Kroll, J. F. (2010). Processing subject-verb agreement in a second language depends on proficiency. Bilingualism: Language and Cognition, 13(2), 87-98. https://doi.org/10.1017/S1366728909990034

Kaan, E. (2002). Investigating the Effects of Distance and Number Interference in Processing Subject-Verb Dependencies: An ERP Study. Journal of Psycholinguistic Research, 31(2), 165-193. https://doi.org/10.1023/A:1014978917769

Liu, D., \& Gleason, J. L. (2002). Acquisition of the article the by nonnative speakers of English: An analysis of four nongeneric uses. SSLA, 24, 1-26. https://doi.org/10.1017/S0272263102001018

López, P. S., \& Benali, T. H. (2018). The use of the definite article in English by Spanish students of English. Error analysis in a learner corpus. In B. Tejero Claver, O. Bernard Cavero \& C. Lechuga Jiménez (Eds.), Investigando en Contenidos de Vanguardia (pp. 263-278). Barcelona: Editorial Gedisa.

López, P. S., \& Benali, T. H. (2019). Analysis of noun (direct object) collocations with the high-frequency verb DO by Spanish students in an online learner corpus. Complutense Journal of English Studies, 27, 99-120. https://doi.org/10.5209/cjes.63337

Mesrawati, M., \& Narius, D. (2019). Students' subject verb agreement errors in writing recount text made by senior high school students. Journal of English Language Teaching, 8(3), 399-407.

Morales, A. (2014). Production and comprehension of verb agreement morphology in Spanish and English child L2 learners: Evidence for the effects of morphological structure. $\mathrm{PhD}$ dissertation, University of Illinois at Urbana-Champaign, United States.

Ndimele, O. (Ed.). (2016). Nigerian languages, literatures, culture and reforms: Festschrift for Ayo bamgbose. Port Harcourt, Nigeria: M \& J Grand Orbit Communications. https://doi.org/10.2307/j.ctvgc602p

Nurjanah, S. (2017). An analysis of subject-verb agreement errors on students' writing. ELT-Echo, 2(1), 13-25. https://doi.org/10.24235/eltecho.v2i1.1590

Quirk, R., \& Greenbaum, S. (1985). A comprehensive grammar of the English language. London: Longman.

Stapa, S., \& Izahar, M. (2010). Analysis of errors in subject-verb agreement among Malaysian ESL learners. Journal of Language Teaching Linguistics and Literature, 16(1), 56-73.

Sufian, M. A., \& Harun, O. (2015). Errors in subject-verb agreement: A study based on Bangladeshi university students. Green University Review of Social Sciences, 2(2), 95-106.

Tafina, A. G., \& Okunade, S. K. (2016). Subject-verb agreement problem among English as second language learners: A case study of one hundred level undergraduates of Federal University of Technology, Minna. International Invention Journal of Education and General Studies, 2(2), 20-27.

Torrado Cespón, M., \& Díaz Lage, J. M. (2017). Error analysis and interlanguage in the use of the term 'ICT' in a learner corpus. Complutense Journal of English Studies, 25, 105-123. https://doi.org/10.5209/CJES.56354

Vigliocco, G., Butterworth, B., \& Garret, M. F. (1996). Subject-verb agreement in Spanish and English: Differences in the role of conceptual constraints. Cognition, 61, 261-298. https://doi.org/10.1016/S0010-0277(96)00713-5

\section{Copyrights}

Copyright for this article is retained by the author, with first publication rights granted to the journal.

This is an open-access article distributed under the terms and conditions of the Creative Commons Attribution license (http://creativecommons.org/licenses/by/4.0/). 